\title{
TGF- $\beta$ Signaling Regulates SLC8A3 Expression and Prevents Oxidative Stress in Developing Midbrain Dopaminergic and Dorsal Raphe Serotonergic Neurons
}

\author{
Enaam Chleilat ${ }^{1}\left(0\right.$, Abhishek Pethe ${ }^{1}$, Dietmar Pfeifer ${ }^{2}$, Kerstin Krieglstein ${ }^{1}$ and \\ Eleni Roussa $1, *$ (1) \\ 1 Institute of Anatomy and Cell Biology, Department of Molecular Embryology, Faculty of Medicine, \\ University of Freiburg, Albertstrasse 17, 79104 Freiburg, Germany; \\ enaam.chleilat@universitaets-herzzentrum.de (E.C.); abhishek.pethe@anat.uni-freiburg.de (A.P.); \\ Kerstin.krieglstein@anat.uni-freiburg.de (K.K.) \\ 2 Department of Hematology, Oncology and Stem Cell Transplantation, University Medical Center Freiburg, \\ University of Freiburg, 79106 Freiburg, Germany; dietmar.pfeifer@uniklinik-freiburg.de \\ * Correspondence: eleni.roussa@anat.uni-freiburg.de
}

Received: 15 March 2020; Accepted: 12 April 2020; Published: 15 April 2020

\begin{abstract}
Calcium homeostasis is a cellular process required for proper cell function and survival, maintained by the coordinated action of several transporters, among them members of the $\mathrm{Na}^{+} / \mathrm{Ca}^{2+}$-exchanger family, such as SLC8A3. Transforming growth factor beta (TGF- $\beta$ ) signaling defines neuronal development and survival and may regulate the expression of channels and transporters. We investigated the regulation of SLC 8 A3 by TGF- $\beta$ in a conditional knockout mouse with deletion of TGF- $\beta$ signaling from Engrailed 1-expressing cells, i.e., in cells from the midbrain and rhombomere 1 , and elucidated the underlying molecular mechanisms. The results show that SLC8A3 is significantly downregulated in developing dopaminergic and dorsal raphe serotonergic neurons in mutants and that low SLC8A3 abundance prevents the expression of the anti-apoptotic protein Bcl-xL. TGF- $\beta$ signaling affects SLC8A3 via the canonical and p38 signaling pathway and may increase the binding of Smad4 to the Slc8a3 promoter. Expression of the lipid peroxidation marker malondialdehyde (MDA) was increased following knockdown of Slc8a3 expression in vitro. In neurons lacking TGF- $\beta$ signaling, the number of MDA- and 4-hydroxynonenal (4-HNE)-positive cells was significantly increased, accompanied with increased cellular 4-HNE abundance. These results suggest that TGF- $\beta$ contributes to the regulation of SLC8A3 expression in developing dopaminergic and dorsal raphe serotonergic neurons, thereby preventing oxidative stress.
\end{abstract}

Keywords: calcium homeostasis; ROS; NCX3; growth factor; neuronal development; hindbrain

\section{Introduction}

Members of the Transforming growth factor beta (TGF- $\beta$ ) family are established molecular players in regulating several cellular processes during development, in health and disease [1-3]. During neuronal development, TGF- $\beta$ s are indispensable molecular determinants for the differentiation of several neuronal populations, among them dopaminergic and serotonergic neurons. Recent studies using animal models with cell type-specific deletion of either TGF- $\beta$ ligands or TGF- $\beta$ signaling have shown severe impairment in the differentiation of individual midbrain dopaminergic and hindbrain serotonergic subpopulations, a process associated with increased neuronal cell death $[4,5]$. 
Cellular ionic homeostasis is a prerequisite for proper cellular function and survival, whereby TGF- $\beta$ s are known to regulate several channels and transporters within or outside the central nervous system [6-9]. Particularly, the link between TGF- $\beta$ s and $\mathrm{Ca}^{2+}$ homeostasis has been documented in several cellular paradigms: In cortical neurons, TGF- $\beta$ regulates L-type $\mathrm{Ca}^{2+}$ channels through MEK, JNK1/2, and p38 MAPK signaling [10]; it increases store-operated $\mathrm{Ca}^{2+}$ entry into megakaryocytes [11]; and it enhances $\mathrm{Ca}^{2+}$ influx pathways and the expression of transient receptor potential canonical channels (TRPCs) in human cardiac fibroblasts. Interestingly, human cardiac fibroblasts express several TRPC-mediated $\mathrm{Ca}^{2+}$ influx pathways, which activate the reverse mode $\mathrm{Na}^{+} / \mathrm{Ca}^{2+}$ exchanger (NCX) [12].

Among the NCX isoformsSLC8A3), the isoform 3 of the $\mathrm{Na}^{+} / \mathrm{Ca}^{2+}$ exchanger (NCX3), is exclusively expressed in excitable cells [13]. It mediates the electrogenic transport of $\mathrm{Na}^{+}$and $\mathrm{Ca}^{2+}$, and contributes to the maintenance of $\mathrm{Ca}^{2+}$ homeostasis. SLC8A3 acts with a stoichiometry of 3:1 and may operate in the forward $\left(\mathrm{Ca}^{2+}\right.$ efflux) or reverse (influx of $\left.\mathrm{Ca}^{2+}\right)$ mode. However, the forward mode is the predominant mode of $\mathrm{Na}^{+} / \mathrm{Ca}^{2+}$ exchanger action. Alternative splicing generates two variants, $\mathrm{AC}$ and $\mathrm{B}$, which display a tissue-specific distribution in mice. The variant B of $S l c 8 a 3$ is mostly expressed in the brain, including substantia nigra pars compacta $(\mathrm{SNc})$ and hindbrain raphe nuclei, whereas the variant AC is predominant in skeletal muscle. The functional significance of SLC8A3 has been appreciated in many studies, as reviewed by Michel et al. (2015) [14]. The capacity of handling $\mathrm{Ca}^{2+}$ during excitotoxicity in neurons has been exclusively attributed to SLC8A3, whereas during brain development, SLC8A3 contributes to the maturation of oligodendrocytes [15]. Mice deficient for Slc8a3 are viable, but they show skeletal muscle fiber necrosis and impaired neuromuscular transmission, associated with reduced motor activity, weakness of the forelimb muscles, and fatigability [16]. Moreover, Slc8a3-deficient mice show impaired hippocampal long-term potentiation and spatial learning [17]. Cortical neurons and hippocampal organotypic cultures from Slc8a3-deficient mice display considerable neuronal death when exposed to oxygen glucose deprivation and reoxygenation [17-19].

Notably, SLC8A3 can be regulated by neurotrophic factors. Indeed, in differentiating neurons, Slc8a3 promoter activity can be enhanced, beyond $\mathrm{Ca}^{2+}$ and retinoid acid, but also by brain-derived neurotrophic factor (BDNF) [20]. It has been proposed that SLC8A3 might play a crucial role in neuronal differentiation and neuronal function. Furthermore, in PC12 cells, nerve growth factor (NGF) increases both isoform 1 and isoform 3 of the $\mathrm{Na}^{+} / \mathrm{Ca}^{2+}$ exchanger (Formisano et al., 2008) [21]. It has also been shown that SLC8A3 basal expression, as well as NGF-induced upregulation of SLC8A3 are regulated by MEK1 (Sirabella et al., 2012) [22].

In the present study, we made use of a mouse line with conditional deletion of TGF- $\beta$ signaling from Engrailed 1 (En1)-expressing cells to investigate the regulation of SLC8A3 in differentiating midbrain dopaminergic and dorsal raphe hindbrain serotonergic neurons. The results show significant downregulation of SLC8A3 in mutants, compared to wild type. We also show a putative regulation of Smad 4 binding to Slc8a3 promoter via TGF- $\beta$ and that low SLC8A3 abundance prevents the expression of the anti-apoptotic Bcl-xL [23]. In neurons lacking TGF- $\beta$ signaling, the number of malondialdehyde (MDA)- and 4-hydroxynonenal (4-HNE) positive cells was significantly increased, accompanied with an increased cellular 4-HNE abundance.

\section{Results}

\subsection{SLC8A3 Expression is Regulated by TGF- $\beta$ Signaling}

In a previous study, we have shown a phenotype in the midbrain and ventral hindbrain of

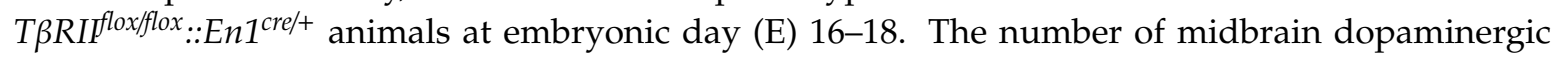
neurons and dorsal raphe serotonergic neurons was significantly decreased in conditional knock out $(c K O)$ animals, compared to wild type $(w t)$, a phenotype accompanied by significantly increased neuronal cell death [4]. 
Impaired $\mathrm{Ca}^{2+}$ homeostasis may underlie neuronal cell death and possibly may be responsible

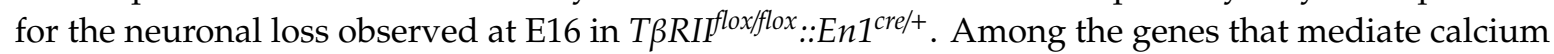
homeostasis, Slc8a3, the isoform 3 of the $\mathrm{Na}^{+} / \mathrm{Ca}^{2+}$ exchanger, is predominantly expressed in substantia nigra dopaminergic neurons and mitochondrial SLC8A3 prevents neuronal degeneration induced by mitochondrial $\mathrm{Ca}^{2+}$ accumulation through interaction with PTEN-induced kinase 1 (PINK) [24].

To test whether impaired SLC8A3 expression might contribute to the phenotype observed in $T \beta R I^{f l o x} / f l o x:: E n 1^{c r e /+}$, first, we determined the SLC8A3 protein expression in the midbrain dopaminergic $(\mathrm{mDA})$ and ventral hindbrain $(\mathrm{vH})$ serotonergic area in $T \beta R I f^{\text {floxfflox }:: E n 1^{c r e /+}}$, by immunohistochemistry at E16 using an antibody against SLC8A3. As shown in Figure 1A-D, in $w t$, SLC8A3 was broadly distributed in both the ventral midbrain (Figure 1A) and hindbrain (Figure 1C), consistent with previous observations [24]. Immunolabeling of a moderate to strong intensity was detected in neurons of the substantia nigra pars compacta (SNc; a2), ventral tegmental area (VTA; a1), and all subpopulations

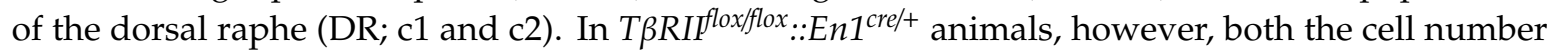
of immunopositive neurons and labeling intensity were considerably decreased in both $\mathrm{mDA}(\mathrm{B}, \mathrm{b} 1$, and b2 for VTA and SNc, respectively) and serotonergic (5-HT) neurons of the dorsal raphe (D, d1, and d2). Indeed, quantification of SLC8A3-positive neurons showed a significant decreased number within the Engrailed 1 area, encompassing both the dorsomedial DR (B7) and the caudal VTA (A10), in $c K O$ embryos, compared to $w t$ littermates (Figure 1E; $6312 \pm 775.6$ and $2452 \pm 325.9$, for $w t$ and $c K O$, respectively, ${ }^{* *} p<0.01$, using the two-tailed unpaired Student's $t$-test, $n=4$ )
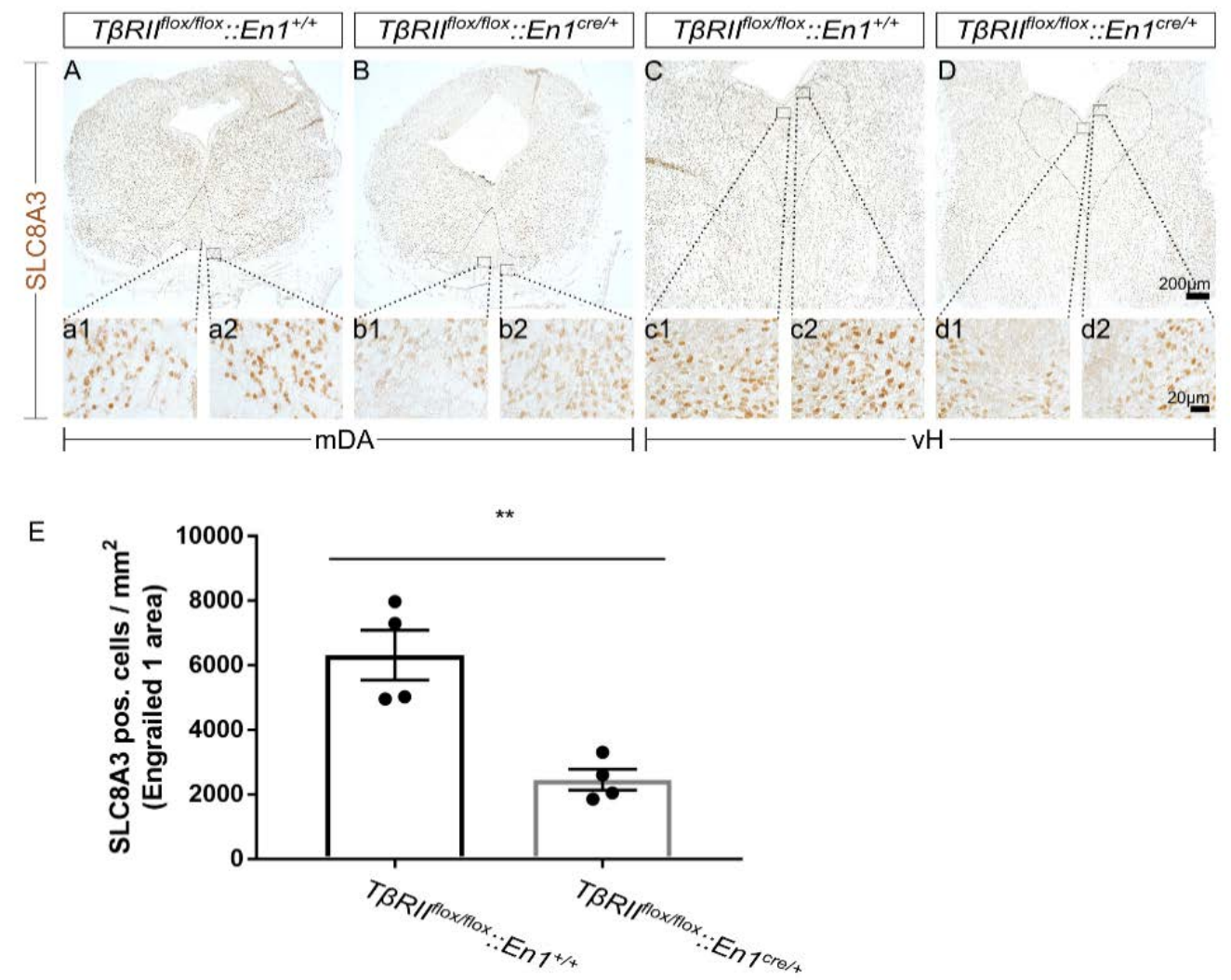

Figure 1. Impaired SLC8A3 expression by loss of TGF- $\beta$ signaling. (A-D): Immunoperoxidase light microscopy for SLC8A3 on fixed coronal sections from the mouse midbrain $(\mathbf{A}, \mathbf{B})$ and ventral hindbrain $(\mathrm{vH} ; \mathbf{C}, \mathbf{D})$ of wild type $(w t)(\mathbf{A}, \mathbf{C})$ and conditional knock out $(c K O)(\mathbf{B}, \mathbf{D})$ at embryonic day 16 shows a decreased labelling intensity in the area of midbrain dopaminergic neurons (a1, a2, b1, and b2 are a higher magnification of the black-boxed areas in $\mathbf{A}$ and $\mathbf{B}$ ) and hindbrain dopaminergic neurons (c1, c2, d1, and $\mathrm{d} 2$ are a higher magnification of the black-boxed areas in $\mathbf{C}$ and $\mathbf{D}$ ) in $c K O$, compared to $w t$. (E) Quantification of SLC8A3-positive cells in the Engrailed $1 \mathrm{area} / \mathrm{mm}^{2}$. ${ }^{* *} p<0.01$, using the two-tailed unpaired Student's $t$-test, $n=4$ /genotype). 


\subsection{Anti-Apoptotic Action of SLC8A3}

We have previously shown increased neuronal cell death accompanied by increased caspase

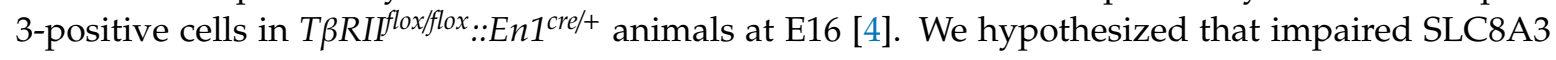
expression contributes to the observed increased neuronal cell death in the $c K O$. Therefore, we performed double immunofluorescence in primary neuronal cultures from $c K O$ at E14 for SLC8A3 and the anti-apoptotic marker Bcl-xL $[23,25]$ (Figure 2A-D). We scored the cells as those with either "high" or "low" SLC8A3 abundance (Representative cells 1-3 in a', arrowheads in b'). As shown in the magnification of the white boxed areas $\left(2 a^{\prime}-2 d^{\prime}\right)$ and representative line scans, high SLC8A3 expression was associated either with high Bcl-xL abundance $(52.2 \pm 2.2 \%$; line scan 1$)$ or with low Bcl-xL expression $(47.8 \pm 2.2 \%$; line scan 2), whereas in low SLC8A3-expressing cells (line scan 3), expression of Bcl-xL was either low or absent. As shown in Figure 2E, there is a statistically significant difference on the Bcl-xL intensity across ventral midbrain/hindbrain neurons between high and low SLC8A3-expressing cell groups. These results imply that low SLC8A3 abundance prevents the expression of the anti-apoptotic protein $\mathrm{Bcl}-\mathrm{xL}$ and may therefore represent a crucial molecular component for neuronal survival.

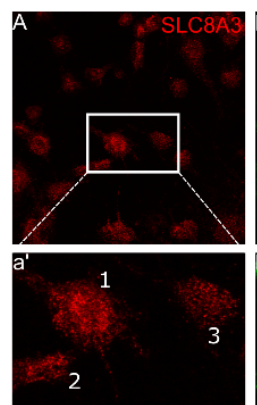

1
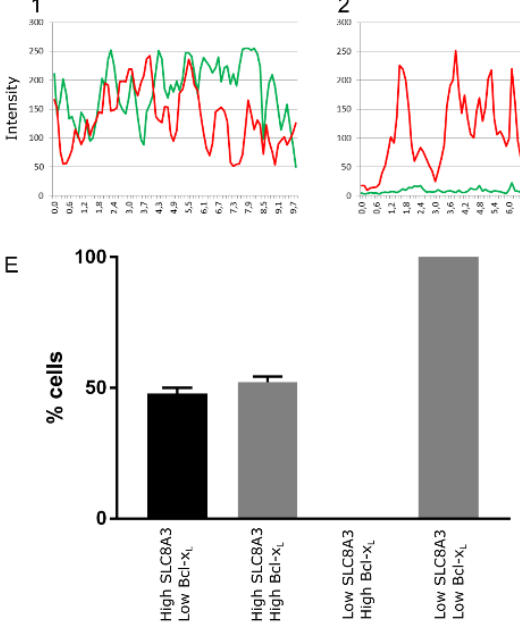

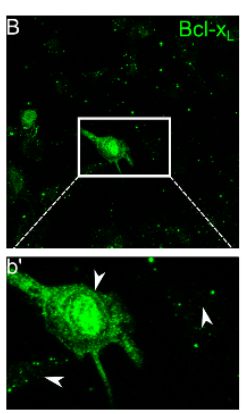

2

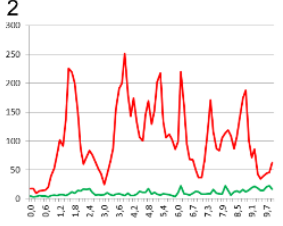

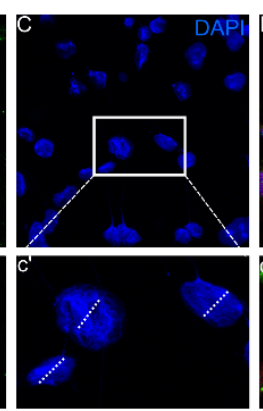

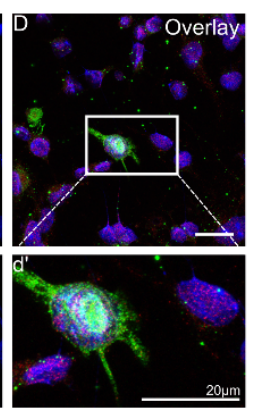

3

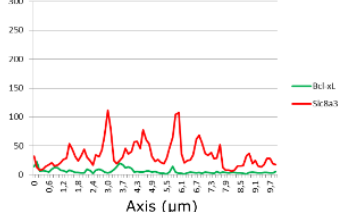

Axis $(\mu \mathrm{m})$

Figure 2. SLC8A3 and Bcl-xL expression correlate in developing Engrailed 1-derived midbrain and hindbrain neurons. (A-D) Confocal double immunofluorescent representative labelling of SLC8A3

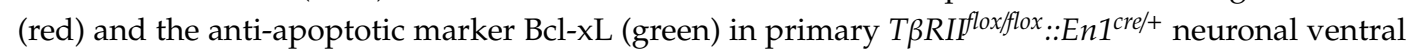
midbrain/hindbrain cultures at E14 show either high or low SLC8A3 expression and high or low Bcl-xL expression. Line scan (1) is a representative image of a neuron with high SLC8A3 expression and high $\mathrm{Bcl}-\mathrm{xL}$ expression (neuron 1 in the magnification of the white boxed area). Line scan (2) depicts neurons with high SLC8A3 expression while Bcl-xL is low (neuron 2 in the magnification of the white boxed area). Line scan (3) shows low cellular SLC8A3 abundance together with low Bcl-xL (neuron 3 in the magnification of the white boxed area). Arrowheads correspond to cells 1-3. (E) Quantification of number of cells (\%) based on high/low SLC8A3 and high/low Bcl-xL expression (total: 96 cells from 3 independent experiments). 


\subsection{Cell-Type-Dependent Regulation of SLC8A3 by TGF- $\beta$}

To investigate whether the activation of TGF- $\beta$ signaling regulates SLC8A3, we first tested the expression of type II TGF- $\beta$ receptor (T $\beta$ RII) in the Lund human mesencephalic (LUHMES) and the mouse MN9D cell lines [26,27]. As shown in the Supplementary Materials, using an antibody against T $\beta$ RII, multiple bands were detected in whole cell homogenates from both MN9D and LUHMES cells. Depending on the species, splice variant, and glycosylation state, the expected size of T $\beta$ RII ranges between 63 and $85 \mathrm{kDa}$. Among other immunoreactive bands, prominent bands at $\sim 65$ and $\sim 70 \mathrm{kDa}$ (arrows) were detected in MN9D and LUHMES cells, respectively. We further asked whether TGF- $\beta$ signaling might affect the protein abundance of SLC8A3. Therefore, MN9D cells were treated with exogenous TGF- $\beta(2 \mathrm{ng} / \mathrm{mL})$ for $60 \mathrm{~min}$, and subsequently SLC8A3 protein abundance was determined by immunoblot analysis (Figure 3A). Using an antibody raised against SLC8A3, an immunoreactive band at $\sim 103 \mathrm{kDa}$, a weaker one at $\sim 110 \mathrm{kDa}$, and a prominent band at $\sim 85 \mathrm{kDa}$ were detected in the controls, and treatment of the cells with TGF- $\beta$ for $60 \mathrm{~min}$ had no significant effect on the SLC8A3 abundance (Figure 3B, $0.96 \pm 0.22$ fold, not significant, $n=3$ using the two tailed unpaired Student's $t$-test. The $\sim 103110 \mathrm{kDa}$ bands, which correspond to the molecular mass of SLC8A3, were quantified). The same results were also obtained using the LUHMES cell line (data not shown). However, MN9D cells are heterogeneous, comprising of progenitor cells and differentiated neurons. To investigate SLC8A3 protein expression in these two cell populations separately, we performed double immunofluorescence for SLC8A3 with the stem cell marker Nestin and the neuronal marker $\beta$-III-tubulin. As shown in Figure 3C-D", G, the abundance of SLC8A3 protein in Nestin-positive cells was low (Figure 3C) and treatment with exogenous TGF- $\beta$ (Figure 3D) had no effect on SLC8A3 immunofluorescence intensity (Figure 3G; $0.94 \pm 0.17$ fold, compared to the untreated controls, not significant, using two-tailed unpaired Student's $t$-test; $n=3$ ). In contrast, differentiated neurons exhibited obvious SLC8A3 immunolabeling (Figure 3E) and treatment with exogenous TGF- $\beta$ (Figure 3F) significantly increased SLC8A3 labeling intensity (Figure 3G; $1.39 \pm 0.13$ fold, compared to the untreated controls, ${ }^{* *} p<0.01$, using two-tailed unpaired Student's $t$-test, $n=7$ ). These data suggest that TGF- $\beta$ differentially regulates SLC8A3 abundance in cells at distinct developmental stages.

\subsection{TGF- $\beta$ Canonical Pathway and p38 Signaling Pathway Regulate Basal SLC8A3 Protein Expression}

MAPKs regulate NCX expression in an NCX-isoform and in a MAPK cascade-specific manner. In PC12 cells, upon NGF stimulation, both ERK1/2 and p38 upregulated NCX3 [22]. To elucidate the pathway by which TGF- $\beta$ signaling regulates SLC8A3, control and TGF- $\beta$-treated $(2 \mathrm{ng} / \mathrm{mL})$ MN9D cells were incubated for $60 \mathrm{~min}$ in the presence or absence of the following inhibitors: Specific Smad3 inhibitor SIS3 $(3 \mu \mathrm{M})$ for blocking the canonical pathway, JNK inhibitor SP600125 $(10 \mu \mathrm{M})$, MEK1 and MEK2 inhibitor PD98059 $(25 \mu \mathrm{M})$, or the p38 inhibitor SB239063 $(10 \mu \mathrm{M})$. Subsequently, double immunofluorescence for $\beta$-III-tubulin and SLC8A3 was performed (Figure 4). In control untreated cells (ctl), blocking of either the MEK1/2 or JNK pathway had no effect on SLC8A3 immunolabeling, as shown in Figure 4A-A'" $, C-C^{\prime \prime \prime}, \mathrm{D}-\mathrm{D}^{\prime \prime \prime}, \mathrm{K}(1.05 \pm 0.1$ fold and $1.10 \pm 0.09$ fold, for inhibition with PD98059 and SP600125, respectively; not significant). Surprisingly, blocking of the canonical, i.e., Smad dependent, pathway by SIS3 (Figure 4B-B" ${ }^{\prime \prime \prime}$ ) or inhibiting the p38 signaling (Figure 4E-E"') significantly increased SLC8A3 fluorescence intensity, compared to untreated cells (Figure 4K: $1.39 \pm 0.11$ fold and $1.25 \pm 0.10$ fold for SIS3 and SB239063, respectively; ${ }^{*} p<0.05$, using the two-tailed unpaired Student's $t$-test, $84-126$ cells/experimental group from $n=5$ ). In TGF- $\beta$-treated MN9D cells (Figure 4F-F"'), SLC8A3 was upregulated in $\beta$-III-tubulin-positive cells (1.37 \pm 0.11 fold; $\left.{ }^{*} p<0.05\right)$ and inhibition of any pathway had no effect on the TGF- $\beta$-dependent increased SLC8A3 abundance (Figure $4 \mathrm{~F}-\mathrm{J}^{\prime \prime \prime}, \mathrm{K}, 1.35 \pm 0.11$ fold, $1.32 \pm 0.18$ fold, $1.37 \pm 0.11$ fold, $1.48 \pm 0.20$ fold, for SIS3, PD98059, SB239063, and SP6000125, respectively * $p<0.05$, compared to the untreated controls, and not significant compared to the TGF- $\beta$ treatment alone, using two-tailed unpaired Student's $t$-test and one-way ANOVA and Bonferroni post-hoc test, 83-107 cells/experimental group, $n=5$ ). 
These data suggest that the TGF- $\beta$ canonical and p38 signaling pathways likely regulate basal SLC8A3 protein levels.
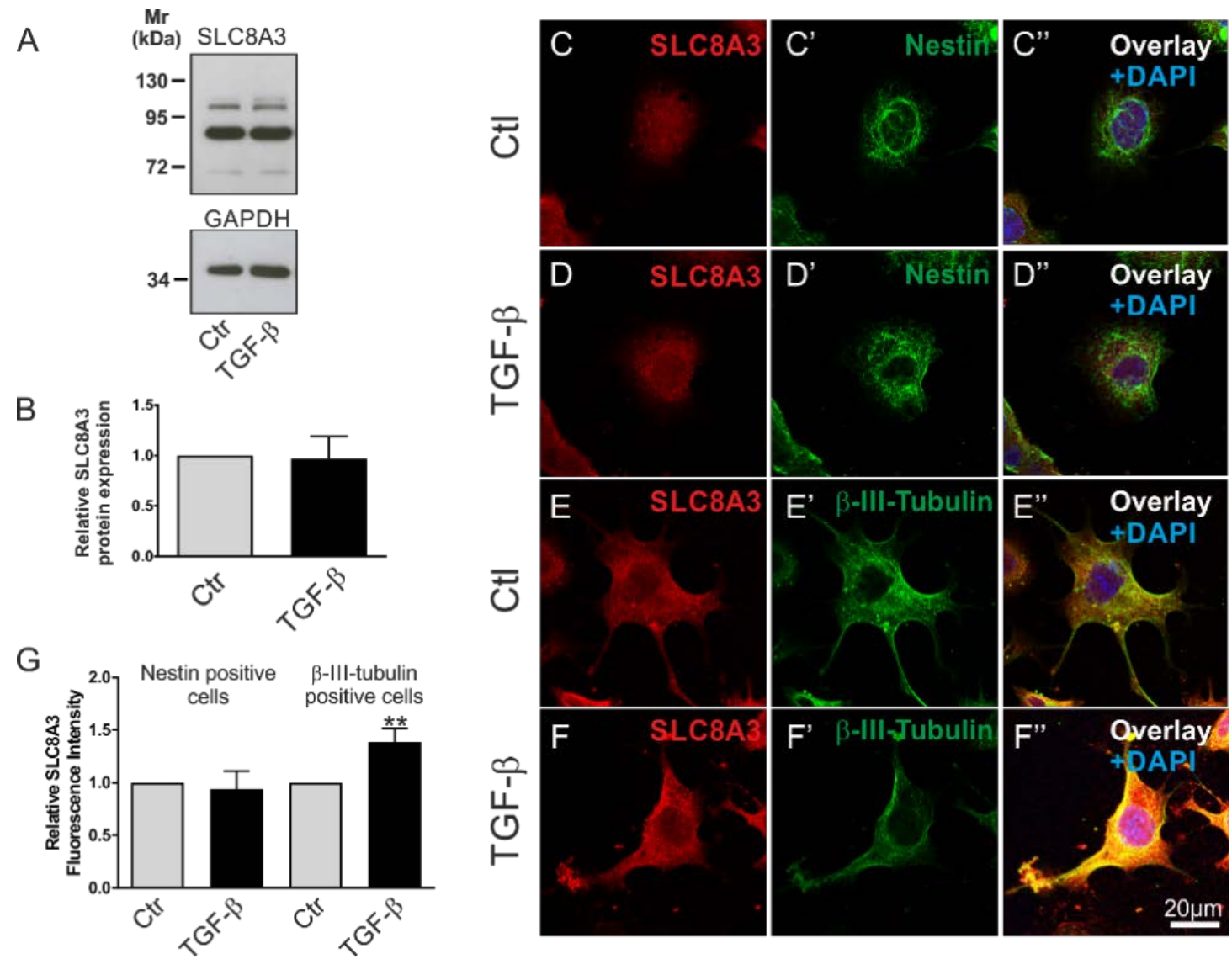

Figure 3. Differential regulation of SLC8A3 in Nestin-positive cells and neurons by TGF- $\beta$. (A) Protein abundance of SLC8A3 by immunoblotting in control MN9D cells in the presence of exogenous recombinant TGF- $\beta$ ( $2 \mathrm{ng} / \mathrm{mL}), 30 \mu \mathrm{g}$ protein was loaded per lane. (B) Quantification, not significant after densitometric analysis of the signal ratio SLC8A3:GAPDH and two-tailed unpaired Student's $t$-test, $n=3$. The value of control (ctl) was set to 1. $\left(\mathbf{C}-\mathbf{F}^{\prime \prime}\right)$ : Confocal double immunofluorescence for SLC8A3 (red) with the stem cell marker Nestin (green; $\mathbf{C}^{\prime}, \mathbf{D}^{\prime}$ ) or the neuronal marker $\beta$-III tubulin (green; $\left.\mathbf{E}^{\prime}, \mathbf{F}^{\prime}\right)$ in MN9D cells in the presence $(\mathbf{D}, \mathbf{F})$ or absence $(\mathbf{C}, \mathbf{E})$ of TGF- $\beta$. (G) Quantification of SLC8A3 immunofluorescence intensity in Nestin-positive cells and $\beta$-III-tubulin-positive cells in controls and following TGF- $\beta$ treatment. ${ }^{* *} p<0.01$, using two-tailed unpaired Student's $t$-test, 30-100 cells/experimental group from 3 to 7 independent experiments. The value of control (ctl) was set to 1 . 

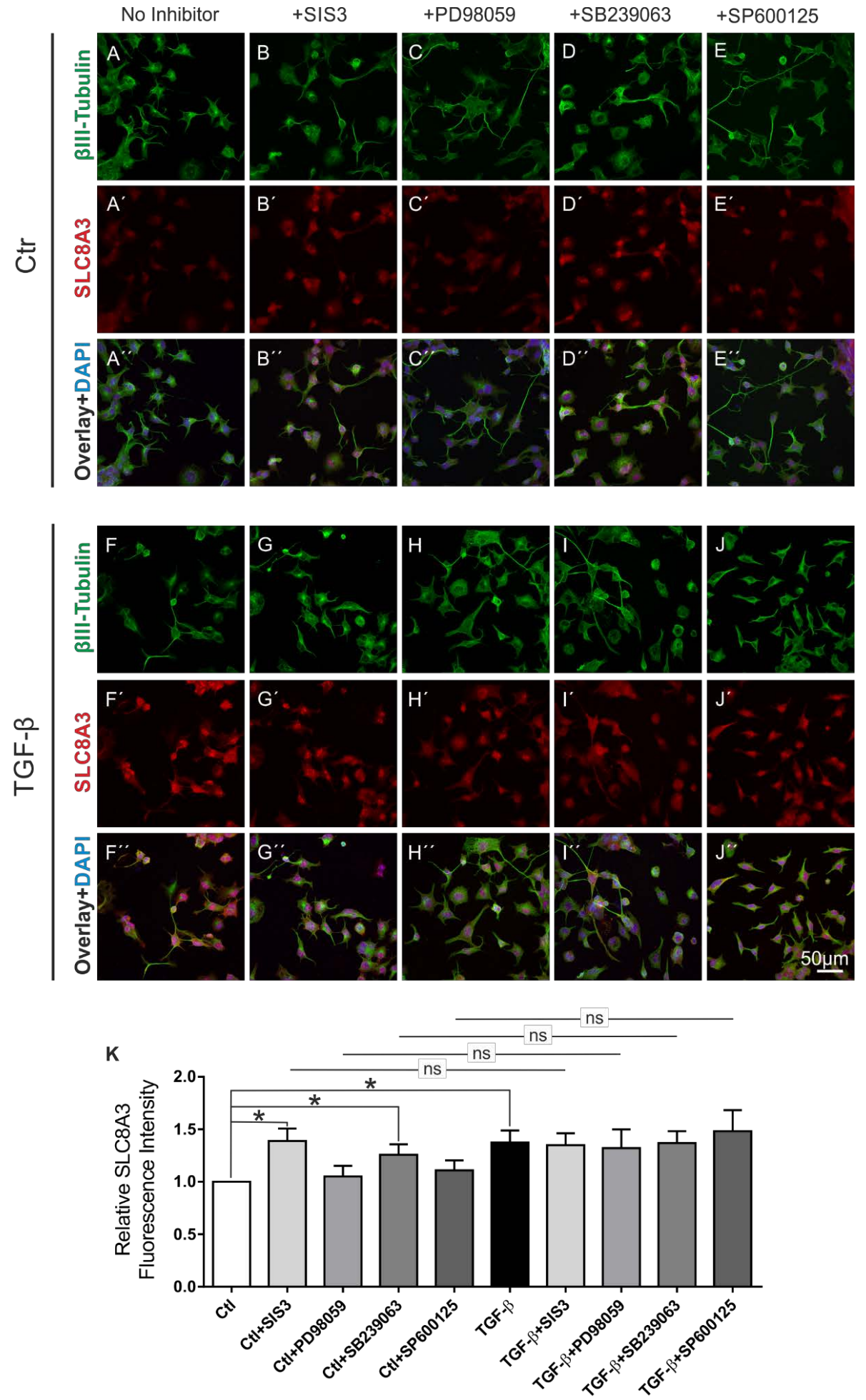

Figure 4. TGF- $\beta$ canonical pathway and p38 pathway regulate basal SLC8A3 levels. Confocal double immunofluorescence for SLC8A3 (red) with the neuronal marker $\beta$-III tubulin (green) in control (ctl; untreated) (A-E) and TGF- $\beta$-treated (F-J) MN9D cells for $60 \mathrm{~min}$ following application of the inhibitor of Smad3 SIS3 (3 $\mu \mathrm{M}$; B-B'" $\left.\mathbf{B}^{\prime \prime}, \mathbf{G}-\mathbf{G}^{\prime \prime \prime}\right)$, or the MAP kinase inhibitor PD98059 (25 $\left.\mu \mathrm{M} ; \mathbf{C}-\mathbf{C}^{\prime \prime \prime}, \mathbf{H}-\mathbf{H}^{\prime \prime \prime}\right)$,

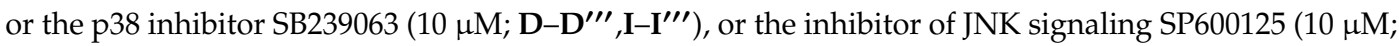
$\left.\mathbf{E}-\mathbf{E}^{\prime \prime \prime}, \mathbf{J}-\mathbf{J}^{\prime \prime \prime}\right),(\mathbf{K})$ Quantification of SLC8A3 fluorescence intensity, ${ }^{*} p<0.05,{ }^{* *} p<0.01$, using the two-tailed unpaired Student's t-test or one-way ANOVA and Bonferroni post hoc test, total 979 cells analyzed from 5 independent experiments. The values of control were set to 1 . 


\subsection{Smad4 Binds to Slc8a3 Promoter}

Having shown that the canonical pathway regulates basal SLC8A3, we next asked whether TGF- $\beta$ directly regulates $\mathrm{Slc} 8 \mathrm{a} 3$. Therefore, we performed a search for conserved Smad binding sequences in the promoter region of $S l c 8 a 3$ (Figure 5A). Indeed, the Slc8a3 promoter on chromosome 14 contains two conserved Smad4 binding sites (sequences in red). To demonstrate that Smad4 binds to the Slc8a3 promoter sequence, chromatin immunoprecipitation (ChIP) was performed in control LUHMES cells and in LUHMES cells after treatment with exogenous TGF- $\beta(2 \mathrm{ng} / \mathrm{mL})$ for $30 \mathrm{~min}$. Smad4 was immunoprecipitated using an antibody against Smad4, and subsequently PCR was performed to amplify DNA fragments bound to Smad4. Therefore, primers flanking the Smad4 binding sequences were used, as shown in Figure 5A (underlined sequences). The results are shown in Figure 5B. Bands at the expected size of $193 \mathrm{bp}$ were detected in the input of the control (lane 1) and treated LUHMES cells (lane 5). Moreover, a band was also detected for the Smad4 binding sequence in the Slc8a3 promoter region following TGF- $\beta$ treatment (lane 8 ), which was more prominent, compared to that in control LUHMES cells (lane 4). Histone 3 (H3) (lanes 3 and 7) and IgG (lanes 2 and 6) were used as a positive and negative control for the immunoprecipitation, respectively. These results imply that Smad4 binding to the Slc8a3 promoter may be regulated by TGF- $\beta$.

A

NG047080

39427

GATGCGGGATGCGGGATGCGGGATGCGGGCTCGACTTCCTCGCTGCTGGT CGAGGAGCGTTCTGAGAGTCTCCC CTCCGCGCGCGAGGATAAATATGCGCGGCTTGTCAGTCAGTGCGG CGCTGTCTCCCAGCTGATAGGGTGACGTTC CGTTTGGAGGCTTGGAGATTGGCTTTTTGATTTGGCTTCTTCCGGCAGCTTAATGGGCAAAGCTCTCCGCTCGCCC $\underline{\underline{ }}$ AGAAACCAGCCTCTCCGCGCGTCCCCTCTGCGCGCGGCGAGGCCGAGACGTCTCCCGCGGTGACAGCGTGCAAG GCGGAGACCCGGCGCGCTCCCAGCCCAGGGAAA

39758

B

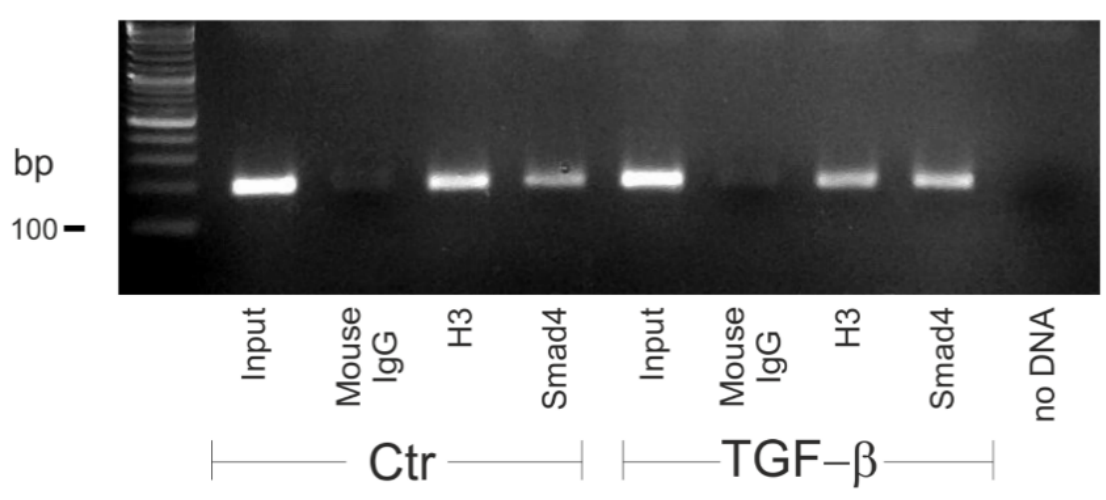

Figure 5. Smad4 specifically binds to the promoter of Slc8a3. (A) Smad4 binding site(s) (red) to the Slc8a3 promoter region. Underlined sequences represent primer sequences used to detect Smad4 binding. (B) PCR following the chromatin immunoprecipitation assay of the control and TGF- $\beta$-treated ( $2 \mathrm{ng} / \mathrm{mL}$ for $30.2 \mathrm{~min}$ ) Lund human mesencephalic (LUHMES) cells demonstrates increased binding of Smad4 to the predicted binding sequence in the promoter region of Slc8a3. Predicted PCR product size $193 \mathrm{bp}$. Histone 3 (H3) and mouse IgG represent the positive and negative control, respectively. The figure is a representative of $n=2$.

\subsection{Knockdown of Slc8a3 is Associated with Oxidative Stress}

The existence of crosstalk between $\mathrm{Ca}^{2+}$ homeostasis and the redox status in the cells has been well established. To investigate a putative link between loss of function of Slc8a3 and oxidative stress, we used malondialdehyde (MDA) expression, a known antigen that can be used for the evaluation of cellular reactive oxygen species ROS levels [28], in MN9D cells transiently transfected with siRNA 
against Slc8a3. To ensure the specificity of siRNA and efficient knockdown of SLC8A3 protein, first, immunofluorescence for SLC8A3 was performed in untransfected MN9D cells (Figure 6A-A"'), in cells treated only with the transfection reagent HiPerFect (Figure 6B- $\mathrm{B}^{\prime \prime \prime}$ ), and in cells transfected either with Alexa 488-labeled negative siRNA (Figure $6 \mathrm{C}-\mathrm{C}^{\prime \prime \prime}$ ) or with labeled Slc8a3-specific siRNA (Figure 6D-D'"'). The SLC8A3 labeling intensity was comparable between untransfected (Figure 6A'), and negative-siRNA-transfected cells (Figure $6 \mathrm{C}^{\prime}$ ). In contrast, SLC8A3 immunofluorescence was nearly abolished in MN9D cells transfected with siRNA specific against Slc8a3 $\left(*\right.$ in Figure $6 \mathrm{D}^{\prime}$, magnification of the white boxed area), compared to non-transfected cells (\#, in Figure $6 \mathrm{D}^{\prime}$, magnification of the white boxed area). Moreover, as shown in Figure $6 \mathrm{E}-6 \mathrm{E}^{\prime \prime \prime}$ and the corresponding magnification of the white boxed areas, MDA labeling was comparable in cells transfected with negative siRNA (green arrows) and non-transfected cells (white arrows). In contrast, as illustrated in Figure $6 \mathrm{~F}-\mathrm{F}^{\prime \prime \prime}$ and the corresponding magnification of the white boxed areas, in cells transfected with specific siRNA against Slc8a3 (green arrows), MDA immunoreactivity was increased, compared to non-transfected cells (white arrow). These results implicate that knockdown of SLC8A3 increases lipid peroxidation.

\subsection{Cell-Type-Specific Deletion of TGF- $\beta$ Signaling is Associated with Oxidative Stress}

To verify whether the results obtained in transfected MN9D cells also apply in En1-derived and T $\beta$ RII-depleted neurons, expression of the lipid peroxidation markers MDA and 4-hydroxynonenal

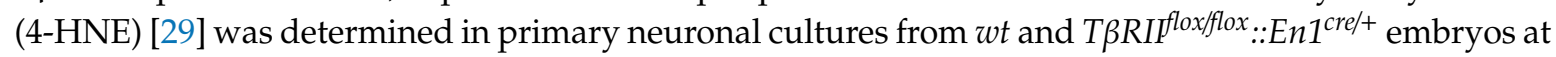
E14. Double immunofluorescence for the neuronal marker $\beta$-III tubulin and MDA or 4-NHE revealed that in $w t$, both MDA (Figure 7A-A ${ }^{\prime \prime}$ ) and 4-HNE (Figure 7C- $\mathrm{C}^{\prime \prime \prime}$ ) were detected in cultures from

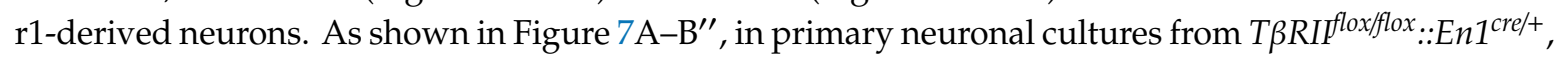
the fluorescence intensity for MDA (Figure 7B- $\mathrm{B}^{\prime \prime}$ and magnification of the white boxed areas $\mathrm{b}^{\prime \prime} 1$ and $\mathrm{b}^{\prime \prime} 2$ ) was comparable to the $w t$ littermate (Figure $7 \mathrm{~A}-\mathrm{A}^{\prime \prime}, \mathrm{E} ; 1.17 \pm 0.25$ fold and $1.09 \pm 0.05$ fold, for $\beta$-III tubulin-negative (Figure $7 b^{\prime \prime} 1$ ) and $\beta$-III tubulin-positive cells (Figure $7 b^{\prime \prime} 2$ ), respectively; not significant, using the two-tailed unpaired Student's $t$-test, total 345 cells ( 150 cells for MDA and 195 cells for $4-\mathrm{HNE}$ ) were examined from $n=3 w \mathrm{t}$ and $n=3 c K O)$. In contrast, the immunofluorescence

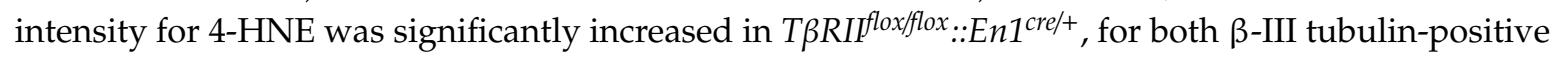
(Figure 7D-B" and high magnification of the white boxed area $d^{\prime \prime} 2$; Figure 7E; $1.54 \pm 0.24$ fold; ${ }^{*} p<0.05$ ) and $\beta$-III tubulin-negative (Figure $7 \mathrm{~d}^{\prime \prime} 1$ and $7 \mathrm{E} ; 1.60 \pm 0.10$ fold; ${ }^{* *} p<0.01$ ) cells, compared to $w$ t (Figure $7 C-C^{\prime \prime}, c^{\prime \prime} 1$ and 2). In addition, the relative number of MDA and 4-HNE-positive cells

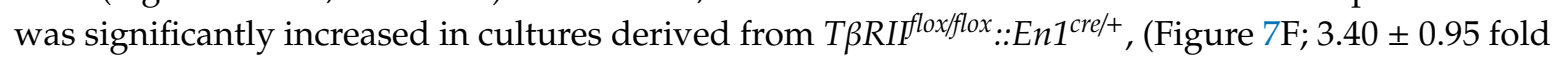
and $2.24 \pm 1.25$ fold, for MDA and 4-HNE, respectively, ${ }^{*} p<0.05$ and ${ }^{* * *} p<0.001$, using the two-tailed unpaired Student's $t$-test $n=3 /$ per genotype), compared to those from $w t$.

These results strongly suggest that the deletion of TGF- $\beta$ signaling in En1-derived neurons leads to oxidative stress and mitochondrial dysfunction. 


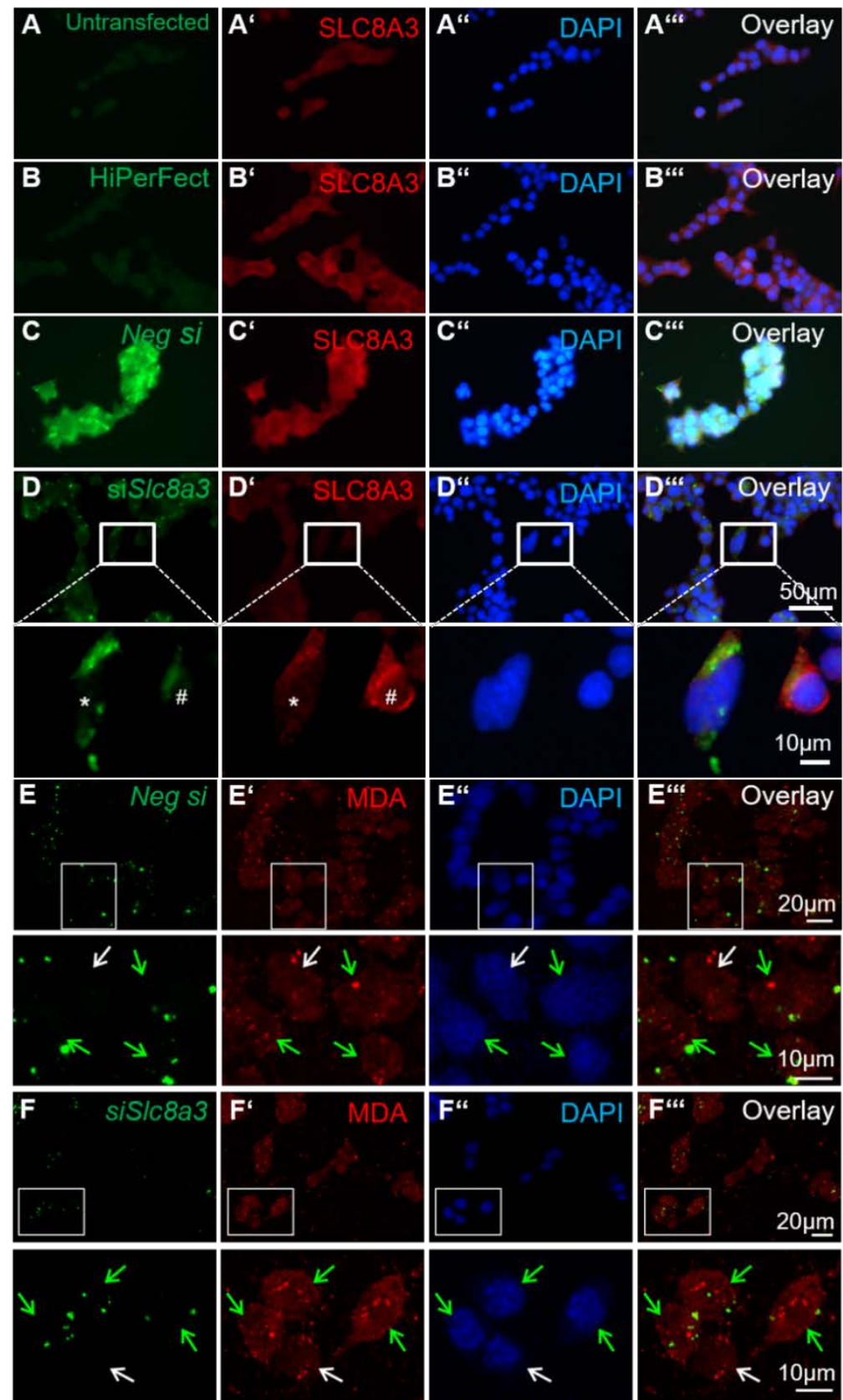

Figure 6. Knockdown of Slc8a3 increases oxidative stress. (A-D) Efficiency of SLC8A3 knockdown. SLC8A3 immunofluorescence in MN9D cells that were either non-transfected (A, untransfected), treated with the transfection agent only (B, HiPerFect), transfected with negative siRNA (C, green, Neg si), or with a specific siRNA against Slc8a3 (green in D). SLC8A3 protein showed no differences between the controls and the cells transfected with negative siRNA but was significantly downregulated in cells transfected with specific Slc8a3 siRNA (magnification of the white boxed areas). (E-E'") Immunofluorescence for the lipid peroxidation marker malondialdehyde (MDA) was comparable between MN9D cells transfected with negative siRNA (green arrows) and non-transfected cells (white arrow). (F-F'" $\left.\mathbf{F}^{\prime \prime}\right)$ MDA immunofluorescence was increased in cells transfected with specific siRNA against Slc8a3. Green arrows indicate successfully transfected cells with specific siRNA against Slc8a3, white arrow points to a cell from the same culture that failed to incorporate Slc8a3 siRNA. 


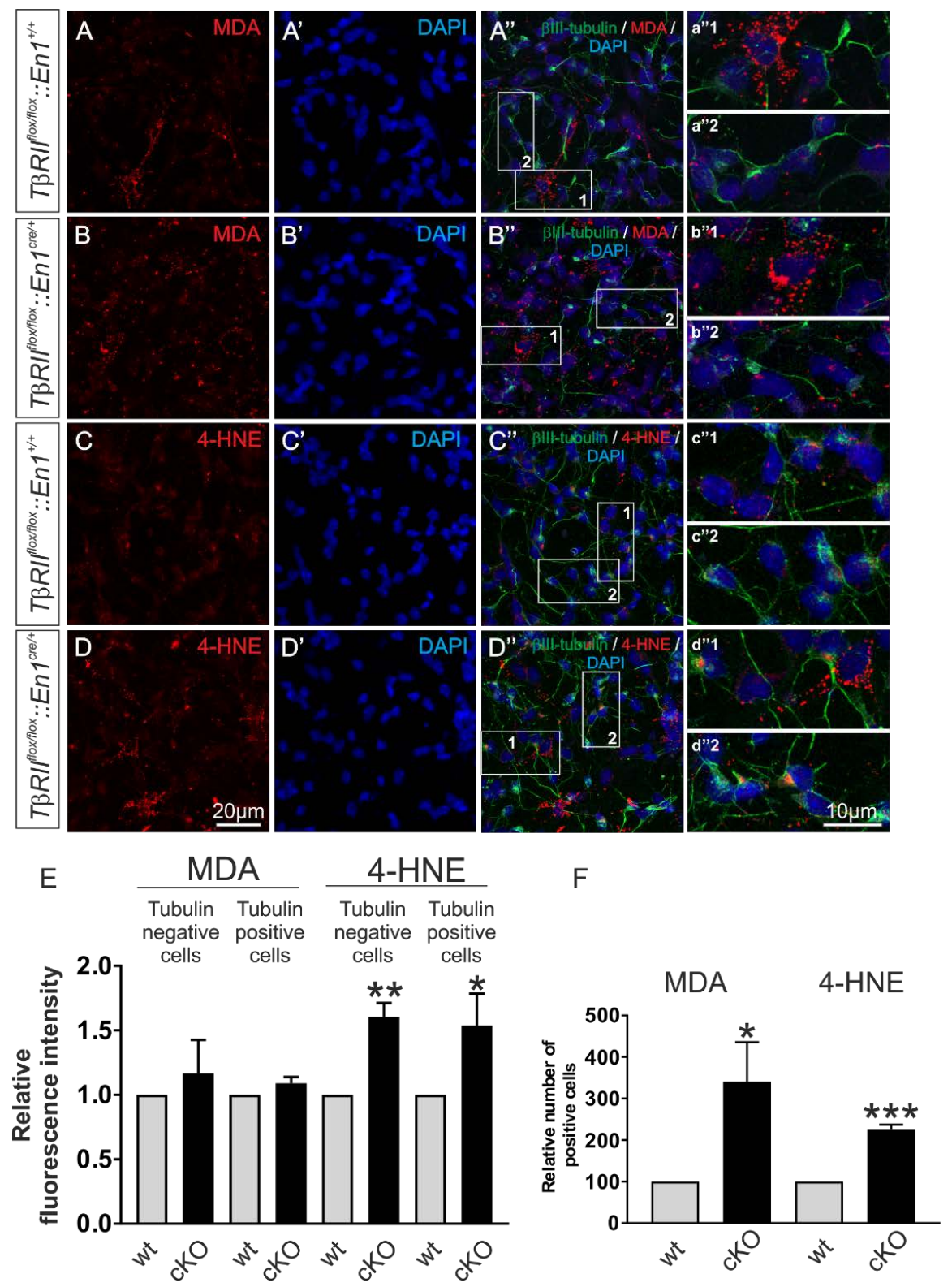

Figure 7. Conditional deletion of TGF- $\beta$ signaling from Engrailed 1-derived $\beta$-III tubulin positive and $\beta$-III tubulin negative cells impairs mitochondrial function. (A-D) Immunofluorescence and subsequent confocal microscopy of the lipid peroxidation markers malondialdehyde (MDA) (A,B) and 4-hydroxynonenal (4-HNE) (C,D) in primary ventral midbrain/hindbrain neuronal cultures from $w t$

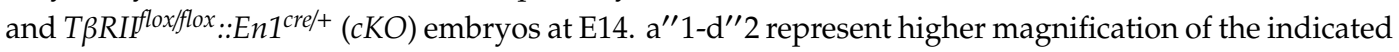
white boxed areas in the respective $\mathrm{A}^{\prime \prime}-\mathrm{D}^{\prime \prime}$. (E,F) Quantification of the MDA and 4-HNE fluorescence intensity (E) and of the number of MDA and 4-HNE-positive cells (F) in the mutant (cKO), compared to $w t$. Abundance of MDA and 4-HNE was significantly increased in the mutant, compared to $w t$ $\left({ }^{*} p<0.05,{ }^{* *} p<0.01\right.$, and ${ }^{* *} p<0.001$, using the two-tailed unpaired Student's $t$-test. A total of 345 cells were analyzed from $n=3$ animals/genotype, the values of $w t$ littermates were set to 1.).

\section{Discussion}

$\mathrm{Ca}^{2+}$ homeostasis is a cellular process required for proper cell function and survival, and maintained by the coordinated action of several transporters, among them members of the $\mathrm{Na}^{+} / \mathrm{Ca}^{2+}$ exchanger family. Our results demonstrate that TGF- $\beta$ plays a role in the regulation of SLC8A3 (NCX3), the isoform 3 of the $\mathrm{Na}^{+} / \mathrm{Ca}^{2+}$ exchanger. Several lines of experimental evidence support this view: In vivo, in mice lacking T $\beta$ RII in En1-derived cells, SLC8A3 was significantly 
downregulated (Figure 1), and the expression of SLC8A3 was positively correlated with the expression of the anti-apoptotic protein Bcl-xL (Figure 2) and negatively correlated with the expression of the lipid peroxidation markers MDA and 4-HNE (Figures 6 and 7). In vitro, TGF- $\beta$ treatment significantly increased SLC8A3 protein expression in neurons (Figure 3) and Smad4 binding to the promoter of Slc8a3 (Figure 5).

What could be the biological significance of these results? During CNS development, SLC8A3 is involved in the maturation of oligodendrocytes [15] and in neuronal differentiation [21]. The physiological role of SLC8A3 has also been highlighted in pathophysiological conditions. SLC8A3 expressed in neurons contributes to the maintenance of intracellular $\mathrm{Ca}^{2+}$ homeostasis during experimental conditions of excitotoxicity and hyperexcitability and is a well-established player for excitotoxicity-derived $\mathrm{Ca}^{2+}$ dysregulation, acting in a neuroprotective manner [30]. In addition, the regulation of $\mathrm{Ca}^{2+}$ homeostasis through the upregulation of SLC8A3 activity apparently protects premyelinating oligodendrocytes from ischemic injury [31]. Our results on primary culture from En1-derived T $\beta$ RII-depleted neurons at E14 implicate that SLC8A3 likely promotes the expression of Bcl-xL (Figure 2A-D), since Bcl-xL was never expressed in $c K O$ cells expressing low SLC8A3. These results point to an anti-apoptotic effect of TGF- $\beta$ signaling in these neuronal populations putatively mediated by the regulation of SLC8A3. Interestingly, certain cells exhibited high SLC8A3 levels, while in others, SLC8A3 expression was low. Based on this observation and taking into consideration that Nestin-positive MN9D cells express lower SLC8A3 levels than $\beta$-III-tubulin-positive MN9D cells (Figure 3), it is reasonable to assume that SLC8A3 may be developmentally regulated. During development, TGF- $\beta$ s may activate distinct signaling pathways, thereby acting pro-apoptotic or anti-apoptotic in a cell-specific and context-dependent manner [32]. Our results add an additional paradigm in this mode of TGF- $\beta$ action. Whereas TGF- $\beta$ had no impact on SLC8A3 protein in Nestin-positive cells in vitro, it caused upregulation of SLC8A3 protein in cells expressing the neuronal marker $\beta$-III-tubulin, suggesting a differential effect of TGF- $\beta$ on cells at distinct developmental states.

Whereas these data are straightforward, the results obtained following the inhibition of known signaling pathways used by TGF- $\beta$ to mediate its effects are more complex (Figure 4). Following inhibition of either the Smad-dependent canonical pathway or the p38 pathway, SLC8A3 in controls was significantly upregulated. In MN9D cells, TGF- $\beta$ is endogenously expressed, which can act in an autocrine mode through other pathways that may drive a compensatory mechanism with an overshooting effect to counteract the loss of Smad and p38 signaling to maintain basal SLC8A3 levels. In vivo, deletion of TGF- $\beta$ signaling leads to the downregulation of SLC8A3, since in the mutant mice, all possible TGF- $\beta$ receptor-mediated signaling pathways are blocked and endogenous TGF- $\beta$ cannot signal at all. Interestingly, in vivo, a loss of TGF- $\beta$ signaling cannot be compensated by other endogenously expressed growth factors.

These results are partly in accordance with those obtained in cortical neurons [10], where TGF- $\beta$ regulates L-type $\mathrm{Ca}^{2+}$ channels via JNK1/2, MEK, and p38 signaling. Moreover, p38 has been shown to upregulate basal SLC8A3 levels and, additionally, upon NGF stimulation of PC12 cells [22]. In the present study, inhibition of the JNK or MAPK signaling pathways had no effect on either basal SLC8A3 or on TGF- $\beta$-dependent SLC8A3 upregulation.

Whether SLC8A3 is expressed only in the cell membrane or in both the plasmalemmal and mitochondrial membrane has been a matter of controversy. However, increasing experimental evidence supports the view that indeed SLC8A3 is expressed in mitochondria as well. More recently, the expression of both the plasmalemmal and mitochondrial $\mathrm{Na}^{+} / \mathrm{Ca}^{2+}$ exchanger was detected in glia cells [33]. In neurons, the $\mathrm{Na}^{+} / \mathrm{Ca}^{2+}$ exchanger is the major player mediating $\mathrm{Ca}^{2+}$ transport back to the cytosol necessary for several neuronal processes, such as neurotransmitter release and synaptic plasticity. Human mesencephalic dopaminergic neurons express both Slc8a2 and Slc8a3 in the mitochondria. Specifically, mitochondrial SLC8A3 contributes to mitochondrial $\mathrm{Na}^{+} / \mathrm{Ca}^{2+}$ exchange, and interacts with PINK to regulate $\mathrm{Ca}^{2+}$ efflux, thus preventing the neuronal degeneration induced by mitochondrial $\mathrm{Ca}^{2+}$ accumulation [24]. Indeed, the role of calcium in the etiology of Parkinson's 
disease has been extensively studied and, as an example, PINK1-associated Parkinson's disease is caused by neuronal vulnerability to calcium-induced cell death [34,35]. Consequently, the blocking of mitochondrial calcium overload has been proposed for therapeutic targeting of oxidative stress and mitochondrial dysfunction in neurodegenerative disorders. In this context, SLC8A2 and SLC8A3 have even been proposed as new molecular targets in Parkinson's disease and potential targets for therapeutic strategies [24].

Mitochondria are an important site for the formation of secondary lipid peroxidation products, such as MDA and 4-HNE. In the present study, we showed that the knockdown of Slc8a3 or deletion of TGF- $\beta$ signaling upregulates the expression of the oxidative stress markers MDA and 4-HNE (Figures 6 and 7). MDA and 4-HNE are the most commonly generated toxic aldehydes, considered to originate under stress conditions, and can react with proteins and/or DNA to form adducts. Depending on their cellular level and the signaling pathways that are able to activate them, MDA and 4-HNE may induce opposite cell responses, such as promote survival or promote cell death. MDA and 4-HNE have been extensively studied and found to be implicated in many pathological processes, such as Alzheimer's disease, cancer, cardiovascular, and liver disease, as reviewed by several studies [29,36,37]. Notably, excess toxic aldehydes apparently influence the function of tyrosine hydroxylase $(\mathrm{TH})$, leading to impaired dopamine synthesis and dopamine insufficiency [38]. Along this line, MDA and 4-HNE have also been linked to Parkinson's disease (PD); in substantia nigra neurons from patients with PD, HNE-protein adducts were significantly increased, as detected by immunohistochemistry [39].

Since Slc8a3-deficient mice are viable [16], it can be excluded that the decreased Slc8a3

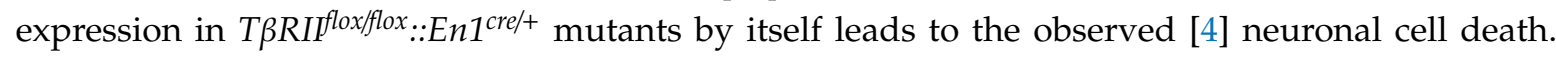
Nevertheless, the observation of binding of Smad4 to the Slc8a3 promoter following TGF- $\beta$ administration in vitro and the fact that cells lacking TGF- $\beta$ signaling with low SLC8A3 never express Bcl-xL could be a starting point for future studies for a better understanding of the role of TGF- $\beta$ signaling during development and degeneration of mDA neurons and in 5-HT-associated clinical disorders. To elucidate whether such increased binding of Smad4 to the Slc8a3 promoter is associated with transcriptional regulation of $S l c 8 a 3$, i.e., whether $S l c 8 a 3$ is a direct target of TGF- $\beta$, functional

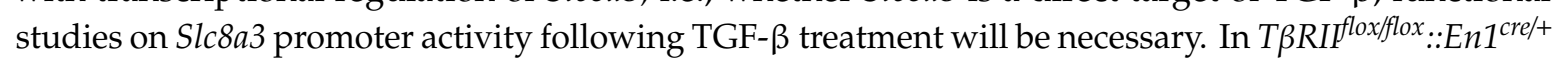
cells, the number of MDA and 4-HNE-positive cells was impressively increased, accompanied by an additional significant increase of cellular 4-HNE levels, compared to $w t$. Although we cannot exclude that a loss of TGF- $\beta$ signaling might have affected other ROS-associated pathways as well, the in vitro data in transfected MN9D cells with specific siRNA against Slc8a3 revealed an upregulation of MDA, implicating that at least in part the data presented in Figure 7 indeed derive from TGF- $\beta$-dependent downregulation of SLC8A3 in differentiating dopaminergic and serotonergic neurons.

In summary, within its limitations, the present study provides the first evidence for a role of TGF- $\beta$ in SLC8A3 regulation in differentiating neurons. We propose a model in which TGF- $\beta$ signaling somehow (directly or indirectly) maintains and/or affects SLC8A3 expression, which, in turn, together with other signaling pathways, suppresses oxidative stress and promotes the survival of differentiating neurons. Whether Slc8a3 is a direct target of TGF- $\beta$, and the interaction mode between TGF- $\beta$ signaling and other signaling pathways need to be further elucidated.

\section{Materials and Methods}

\subsection{Animals}

All protocols were carried out in accordance with German ethical guidelines for laboratory animals and approved by the Institutional Animal Care and Use Committee of the University of Freiburg (authorizations: G11/56 (01 July 2011) and X-16/10F,(11 August 2016)). The T $\beta R$-Ifloxfflox mice were generated by Chityl et al. [40] and provided by Dr. Harold Moses (Vanderbilt-Ingram Cancer Center, Nashville, TN, USA). En1-cre mice were provided by Dr. Wolfgang Wurst [41]. Mice with two 


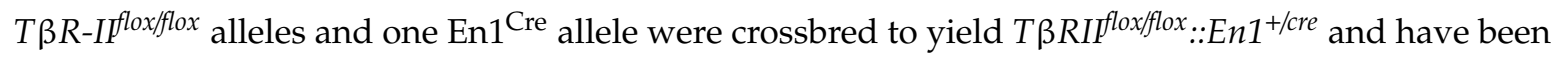
previously described [4].

\subsection{Genotyping}

Genotyping was performed as previously described [4]. For detection of the T $\beta$ RII wild type $(w t)$ or floxed gene, the following primers were used: $5^{\prime}$-TAA ACA AGG TCC GGA GCC CA-3' as the forward primer and $5^{\prime}$-ACT TCT GCA AGA GGT CCC CT-3' as the reverse primer. The expected band for the floxed gene is $540 \mathrm{bp}$, while the expected band for the $w t$ gene is $420 \mathrm{bp}$. For detection of the En1-Cre gene, the following primers were used. $5^{\prime}$-GAG ATT TGC TCC ACC AGA GC- $3^{\prime}$ as the forward primer, $5^{\prime}$-AGG CAA ATT TTG GTG TAC GG-3' as the reverse primer for the mutant and 5'-CGA GTC GCG CTG ACT TTT AG-3' as the reverse primer for the WT. The expected band for the wt gene is $250 \mathrm{bp}$, while the expected band for the Cre gene is $181 \mathrm{bp}$. PCR was performed with the following cycle conditions: denaturation at $93{ }^{\circ} \mathrm{C}$ for $3 \mathrm{~min}$, and 40 cycles of PCR amplification at $93^{\circ} \mathrm{C}$ for $30 \mathrm{~s}$ and $58{ }^{\circ} \mathrm{C}$ for $30 \mathrm{~s}$, and elongation at $72{ }^{\circ} \mathrm{C}$ for $30 \mathrm{~s}$, followed by $72{ }^{\circ} \mathrm{C}$ for $5 \mathrm{~min}$. PCR products were run on a $2 \%$ agarose gel in Tris-acetate-EDTA (TAE) buffer at $100 \mathrm{~V}$, and then photodocumented using a UV transluminator.

\subsection{Immunohistochemistry}

Brains from $w t$ and $c K O$ embryos were fixed in $4 \%$ paraformaldehyde (PFA), cryoprotected, and cut into $10-\mu \mathrm{m}$ serial coronal sections. Immunohistochemistry was performed as described earlier [42]. Rabbit polyclonal anti-SLC8A3 (1:300) was used as the primary antibody. Goat anti- rabbit-biotin or anti-rabbit IgG coupled either to horseradish peroxidase were used as secondary antibodies.

Diaminobenzidene (DAB) immunohistochemically stained samples were first imaged using the Zeiss Axio Imager M2. Representative images of DAB areas from 5 Engrailed 1-expressing sections were acquired per animal. Visual manual multi-point counting was conducted using ImageJ of each image at the acquired scaled size of $142.10 \mu \mathrm{m} \times 106.48 \mu \mathrm{m}$ (objective $100 \times$; surface area $15,130.808 \mu \mathrm{m}^{2}$ ). The counted values of each image at that size were pooled together in the analysis (sum area was $75,654.04 \mu \mathrm{m}^{2}$ ). The final step was a unit conversion to $\mathrm{mm}^{2}$.

\subsection{Cell Culture of E14 Ventral Mesencephalon and Ventral Hindbrain}

The ventral mesencephalon and ventral hindbrain (corresponding to rhombomere 1) from $w t$ and $c K O$ mice at E14 was isolated as described earlier [4,42]. The ventral midbrain and ventral hindbrain were dissected from E14 embryos and incubated in $0.25 \%$ trypsin for 15 min at $37^{\circ} \mathrm{C}$. Tissue from each littermate was separately dissociated by gentle titration using fire-polished Pasteur pipettes. Dissociated cells were resuspended in high glucose DMEM-F12 medium supplemented with $0.25 \%$ bovine serum albumin (BSA), $0.5 \% \mathrm{~N} 1$ additives, $1 \%$ glutamin, $0.2 \%$ insulin, $33 \mathrm{mM}$ glucose, and $100 \mathrm{U} / \mathrm{mL}$ penicillin, $0.5 \mu \mathrm{g} / \mathrm{mL}$ streptomycin, and $100 \mu \mathrm{g} / \mathrm{mL}$ neomycin (PSN; Gibco Life Technologies Thermo Fisher Scientific, 63303 Dreieich, Germany ), and plated onto polyornithin and laminin overnight coated $12-\mathrm{mm}^{2}$ glass cover slips in 24 -well plates at a density of 100,000 cells/cover slip. Cells were fixed in $4 \%$ PFA and processed for immunocytochemistry.

\subsection{Cell Culture of MN9D and LUHMES Cells}

Lund human mesencephalic (LUHMES), a v-myc-expressing human neuroprogenitor line [26], and MN9D, a hybridoma cell line by fusing embryonic primary cells from the mouse ventral midbrain with cells from the mouse neuroblastoma cell line N18TG2 [27], were used for in vitro experiments. LUHMES cells were cultured on surfaces coated with $0.01 \%$ poly-L-ornithine and fibronectin $(2 \mu \mathrm{g} / \mathrm{mL}$, Sigma Aldrich, 82024 Taufkirchen, Germany) in proliferation medium, consisting of DMEM:F12 medium supplemented with 1\% N2 supplement and 40 ng/mL FGF2 (R\&D Systems; 65205 Wiesbaden, Germany) at a seeding density of $5 \times 10^{4}$ cells $/ \mathrm{cm}^{2}$. MN9D cells were plated on poly-D-lysine-coated wells or coverslips and cultured in DMEM/F-12, supplemented with $10 \%$ FBS, and $1 \%$ PSN. Cells were 
passaged when confluent, and incubated in a $5 \% \mathrm{CO}_{2} / 95 \% \mathrm{O}_{2}$ atmosphere at $37^{\circ} \mathrm{C}$. Cells were allowed to differentiate by treatment with $1 \mathrm{mM}$ butyric acid for at least 6 days [43]. In undifferentiated and differentiated MN9D cells, serum was retrieved overnight and cells were subsequently treated with recombinant TGF- $\beta$ ( $2 \mathrm{ng} / \mathrm{mL}$ ) (R\&D Systems) for $1 \mathrm{~h}$. When the inhibitors of the signaling pathways were used, cells were pre-incubated with the inhibitors for approximately $20 \mathrm{~min}$, before the application of TGF- $\beta$. Control and treated cells were either $4 \%$ PFA fixed for immunofluorescence, or processed for protein extraction and immunoblotting.

\subsection{Immunocytochemistry}

Immunocytochemistry on primary cultures from the ventral midbrain and hindbrain and on MN9D cells was performed essentially as described earlier [41]. Cells were fixed in 4\% PFA/PBS for 30 min at RT, washed with PBS, treated with $1 \%$ SDS/PBS for 5 min, blocked with $1 \%$ BSA/PBS for $15 \mathrm{~min}$, and incubated with primary antibodies overnight at $4{ }^{\circ} \mathrm{C}$ (mouse monoclonal antibodies anti-Nestin 1:100, anti- $\beta$ III-tubulin 1:200 (Developmental Studies Hybridoma Bank, Iowa, USA, Cat\# Rat-401 and \#E7, respectively), rabbit polyclonal anti-SLC8A3 (NCX3; Cat\# orb11106, Biozol, 85286 Eching, Germany) 1:100, mouse monoclonal anti-Bcl-xL 1:200 (Cat\# sc-136132, Santa Cruz Biotechnology, Dallas, TX, USA), rabbit polyclonal anti MDA 1: 500, and rabbit polyclonal anti-4-HNE 1:500 (Cat\# MDA11-S and Cat\# HNE11-C AlphaDiagnostics, San Antonio, TX, USA). Cells were washed with PBS, and incubated with either donkey anti-rabbit IgG Alexa Fluor 568 and/or donkey anti-mouse Alexa Fluor 488 at 1:400 $1 \mathrm{~h}$ at RT. Cells were washed in PBS, mounted with Flouromount-G containing DAPI, and viewed with a Leica TCS SP8 confocal microscope (Leica Microsystems, 35578 Wetzlar Germany). Following double labeling with SLC8A3 and Bcl-xL, cells were scored as those with either high or low SLC8A3 abundance, and the subsequently intensity of Bcl-xL was determined by line scans. Using LAS X software (3.7.0.20979; Leica Microsystems), the threshold was set at maximum intensity of 202; "high SLC8A3" neurons had a maximum intensity of $>203$ and "low SLC8A3" cells had a maximum value $<201$.

\subsection{Image Acquisition and Analysis}

Images were acquired with a Leica TCS SP8 confocal microscope using a CS2 $40 \times 1.40$ oil objective lens. The immunofluorescence intensity for SLC8A3 was determined. Within each experiment, the confocal microscope settings (laser power, detector gain, and amplifier offset) were kept the same for all scans in which the protein expression was compared. Z-stacks of 16-35 optical sections with a step size of $0.5 \mu \mathrm{m}$ were taken for at least 4 separate fields of view for each experimental condition. Maximum intensity projections were created from the z-stacks. To quantify the protein expression, LAS $\mathrm{x}$ software was used to measure the average intensity within the soma. Background substraction was applied to the images. After quantification data were normalized to the mean of controls. Representative images for each figure were processed identically.

\subsection{Immunoblotting}

Protein isolation from MN9D cells, electrophoresis, and blotting procedures were performed as described [9]. Protein concentration was determined by a Thermo Scientific NanoDrop 2000 spectrophotometer (absorbance at $280 \mathrm{~nm}$ ). Primary antibodies were diluted: Rabbit polyclonal antibody anti- SLC8A3 (NCX3 Cat\# orb11106, Biozol,) 1:1000, rabbit polyclonal anti-TßRII (C-16) 1:1000 (Cat\# Sc-220, Santa Cruz Biotechnology, Dallas, TX, USA), and mouse monoclonal anti-GAPDH 1:20,000 (Cat\# ab8245, Abcam, Cambridge, UK). Blots were developed in enhanced chemiluminescence reagents, and signals were visualized on $\mathrm{X}$-ray films. Films were scanned and the signal ratio protein of interest:housekeeping gene was quantified densitometrically. Differences in the signal ratio were tested for significance using two-tailed unpaired Student's $t$-test. Results with levels of * $p<0.05$ were considered significant. 


\subsection{Chromatin Immunoprecipitation Assay}

Chromatin immunoprecipation (ChIP) assays and PCR were performed on control and TGF- $\beta$-treated LUHMES cells using an EZ ChIP kit (Merck Millipore, Darmstadt, Germany), as described [9] and following the manufacturer's instructions. Briefly, DNA was crosslinked to protein with $1 \%$ paraformaldehyde. Cell lysates were obtained by scraping followed by sonication (Diagenode, Bioruptor Sonication Device; Ougreé, Belgium) to shear cellular DNA. Overnight immunoprecipitations were performed with histone 3 (mouse monoclonal anti-H3; Cat \# MABE923, Merck, 64293 Darmstadt, Germany), IgG (mouse polyclonal Cat\# 12-371 from Merck-Millipore), and anti-Smad4 (rabbit polyclonal, Cat\# 38454, Cell Signaling, 60314 Frankfurt, Germany) antibody. On the next day the crosslinks were reversed, and bound DNA was purified. Subsequently, PCR was performed using primers specific for Smad4 promoter sequences in human SLC8A3. Primer sequences (with their starting positions in the promoter sequence; NG047080) were: Smad4 forward: 5'-CGAGGAGCGTTCTGAGAGTC-3' , Smad4 reverse: 5'-GCGGAGAGGCTGGTTTCTG-3'. The SLC8A3 promoter sequence was retrieved using EnsEMBL, and the conserved Smad4 binding sequence was identified by sequence alignment using ClustalW (EMBL-EBI).

\subsection{Transient Transfection of MN9D Cells}

MN9D cells were plated on 12-mm² glass cover slips in a density of 50,000 cells per well $24 \mathrm{~h}$ prior to transfection. Cells were transiently transfected with Alexa 488-labeled siRNA specifically targeting mouse Slc8a3 mRNA (purchased from Qiagen, 40724 Hilden, Germany) using HiPerFect reagent (Qiagen), following the manufacturer's instructions as previously described [44]. Briefly, $30 \mu \mathrm{L}$ of HiPerFect and $1 \mathrm{~mL}$ of medium without FBS and PSN were thoroughly vortexed before $10 \mathrm{nM}$ siRNA was added. To allow the formation of HiPerFect-siRNA complexes, the mixture was incubated in the dark for $30 \mathrm{~min}$ at RT before being cautiously pipetted onto the cells. A sequence that revealed no homology with any known mammalian gene was labeled with Alexa 488 (AllStars Negative Control siRNA, Qiagen) and was used as a control, i.e., negative siRNA. Then, $24 \mathrm{~h}$ following transfection, cells were processed for immunofluorescence.

\subsection{Statistics}

Data are presented as the mean \pm standard error of mean (SEM). Statistical analysis was performed using the two-tailed unpaired Student's $t$-test or one-way ANOVA and Bonferroni post-hoc test. Differences were considered statistically significant at ${ }^{*} p<0.05,{ }^{* *} p<0.01$, and ${ }^{* *} p<0.001$.

Supplementary Materials: Supplementary materials can be found at http://www.mdpi.com/1422-0067/21/8/2735/ s1.

Author Contributions: Conceptualization, K.K. and E.R.; methodology, E.C.; validation, E.C., K.K. and E.R.; formal analysis, E.C., A.P., D.P. and E.R.; resources, K.K.; writing-original draft preparation, E.R.; writing-review and editing, E.R., E.C., A.P., and K.K.; supervision, E.R.; project administration, E.R.; funding acquisition, K.K. All authors have read and agreed to the published version of the manuscript.

Funding: This research was funded by DEUTSCHE FORSCHUNGSGEMEINSCHAFT (DFG), grant number Kr1477/10-3.

Acknowledgments: This work is dedicated to our colleague, Fabian Cardenas Lara. We thank Ellen Gimbel and Lidia Koschny for technical assistance and Marina Giannaki for treatment of MN9D cells.

Conflicts of Interest: The authors declare no conflict of interest. The funders had no role in the design of the study; in the collection, analyses, or interpretation of data; in the writing of the manuscript, or in the decision to publish the results. 


\section{Abbreviations}

\begin{tabular}{|c|c|}
\hline 4-HNE & 4-hydroxynonenal \\
\hline $5-\mathrm{HT}$ & 5-hydroxytryptamine \\
\hline Bcl-xL & B-cell lymphoma-extra large \\
\hline BDNF & Brain derived neurotrophic factor \\
\hline $\mathrm{cKO}$ & Conditional knockout \\
\hline DMEM & Dulbecco's Modified Eagle Medium \\
\hline DR & Dorsal raphe \\
\hline E\# & Embryonic day \\
\hline En1 & Engrailed 1 \\
\hline ERK1/2 & Extracellular signal-regulated kinases-1/2 \\
\hline GAPDH & Glyceraldehyde 3-phosphate dehydrogenase \\
\hline $\mathrm{H} 3$ & Histone 3 \\
\hline $\mathrm{JNK} 1 / 2$ & c-Jun N-terminal kinases \\
\hline L-type $\mathrm{Ca}^{2+}$ & Long-lasting calcium channel \\
\hline LUHMES & Lund Human Mesencephalic \\
\hline MAPK & Mitogen-activated protein kinase \\
\hline MEK & Mitogen-activated protein kinase kinase \\
\hline $\mathrm{mDA}$ & Midbrain dopaminergic \\
\hline MDA & Malondialdehyde \\
\hline NCX3 & $\mathrm{Na}^{+} / \mathrm{Ca}^{2+}$ exchanger 3 \\
\hline NGF & Nerve growth factor \\
\hline PC12 & Pheochromocytoma of the rat adrenal medulla \\
\hline PD & Parkinson's disease \\
\hline PINK1 & PTEN-induced kinase 1 or PTEN-induced putative kinase 1 \\
\hline ROS & Reactive oxygen species \\
\hline siRNA & Silencing RNA \\
\hline SLC8A3 & Solute carrier Family 8 member A3 \\
\hline Smad & Small mother against decapentaplegic \\
\hline $\mathrm{SNc}$ & Substantia nigra pars compacta \\
\hline TGF- $\beta$ & Transforming growth factor beta \\
\hline TRPC & Transient receptor potential canonical channels \\
\hline $\mathrm{T} \beta \mathrm{RII}$ & Type II TGF- $\beta$ receptor \\
\hline $\mathrm{vH}$ & Ventral hindbrain \\
\hline VTA & Ventral tegmental area \\
\hline Wt & Wildtype \\
\hline
\end{tabular}

\section{References}

1. Derynck, R.; Miyazono, K. TGF- $\beta$ and The TGF- $\beta$ Family. In The TGF- $\beta$ Family; Derynck, R., Miyazono, K., Eds.; Cold Spring Harbor Laboratory Press: New York, NY, USA, 2008; pp. 29-43. [CrossRef]

2. Krieglstein, K.; Zheng, F.; Unsicker, K.; Alzheimer, C. More than being protective: Functional roles of TGF- $\beta$ /activin signaling pathways at central synapses. Trends Neurosci. 2011, 34, 421-429. [CrossRef]

3. Akhurst, R.J.; Hata, A. Targeting the TGF- $\beta$ signalling pathway in disease. Nat. Rev. Drug Discov. 2012, 11, 790-811. [CrossRef]

4. Chleilat, E.; Skatulla, L.; Rahhal, B.; Hussein, M.T.; Feuerstein, M.; Krieglstein, K.; Roussa, E. TGF- $\beta$ signaling regulates development of midbrain dopaminergic and hindbrain serotonergic neuron subgroups. Neuroscience 2018, 381, 124-137. [CrossRef]

5. Chleilat, E.; Mallmann, R.; Spanagel, R.; Klugbauer, N.; Krieglstein, K.; Roussa, E. Spatiotemporal role of transforming growth factor beta 2 in developing and mature mouse hindbrain serotonergic neurons. Front. Cell. Neurosci. 2018, 13, 427. [CrossRef]

6. Roux, J.; Carles, M.; Koh, H.; Goolaerts, A.; Ganter, M.T.; Chesebro, B.B.; Howard, M.; Houseman, B.T.; Finkbeiner, W.; Shokat, K.M.; et al. Transforming growth factor beta1 inhibits cystic fibrosis 
transmembrane conductance regulator-dependent cAMP-stimulated alveolar epithelial fluid transport via a phosphatidylinositol 3-kinase-dependent mechanism. J. Biol. Chem. 2010, 285, 4278-4290. [CrossRef]

7. Rathore, K.I.; Redensek, A.; David, S. Iron homeostasis in astrocytes and microglia is differentially regulated by TNF- $\alpha$ and TGF- $\beta 1$. Glia 2012, 60, 738-750. [CrossRef] [PubMed]

8. Yi, S.; Pierucci-Alves, F.; Schultz, B.D. Transforming growth factor- $\beta 1$ impairs CFTR-mediated monolayer via the p38 MAPK pathway. Am. J. Physiol. Cell Physiol. 2013, 305, C867-C876. [CrossRef] [PubMed]

9. Khakipoor, S.; Ophoven, C.; Schrödl-Häußel, M.; Feuerstein, M.; Heimrich, B.; Deitmer, J.W.; Roussa, E. TGF- $\beta$ Signaling directly regulates transcription and functional expression of the electrogenic sodium bicarbonate cotransporter 1, NBCe1 (SLC4A4), via Smad4 in mouse astrocytes. Glia 2017, 65, 1361-1375. [CrossRef] [PubMed]

10. Liu, Z.; Sheng, J.; Peng, G.; Yang, J.; Chen, W.; Li, K. TGF- $\beta 1$ regulation of p-JNK and L-type calcium channel Cav1.2 in cortical neurons. J. Mol. Neurosci. 2018, 64, 374-384. [CrossRef]

11. Yan, J.; Schmid, E.; Almilaji, A.; Shumilina, E.; Borst, O.; Laufer, S.; Gawaz, M.; Lang, F. Effect of TGF on calcium signaling in megakaryotes. Biochem. Biophys. Res. Commun. 2015, 461, 8-13. [CrossRef]

12. Ikeda, K.; Nakajima, T.; Yamamoto, Y.; Takano, N.; Tanaka, T.; Kikuchi, H.; Oguri, G.; Morita, T.; Nakamura, F.; Komuro, I. Roles of transient receptor potential canonical (TRPC) channels and reverse-mode $\mathrm{Na}^{+} / \mathrm{Ca}^{2+}$ exchanger on cell proliferation in human cardiac fibroblasts: Effects of transforming growth factor 1. Cell Calcium 2013, 54, 213-225. [CrossRef] [PubMed]

13. Michel, L.Y.; Verkaart, S.; Koopman, W.J.; Willems, P.H.; Hoenderop, J.G.; Bindels, R.J. Function and regulation of the $\mathrm{Na}^{+}-\mathrm{Ca}^{2+}$ exchanger NCX3 splice variants in brain and skeletal muscle. J. Biol. Chem. 2014, 289, 11293-11303. [CrossRef] [PubMed]

14. Michel, L.Y.; Hoenderop, J.G.; Bindels, R.J. Towards understanding the role of the $\mathrm{Na}^{+}-\mathrm{Ca}^{2+}$ exchanger isoform 3. Rev. Physiol. Biochem. Pharmacol. 2015, 168, 31-57. [CrossRef] [PubMed]

15. Boscia, F.; D’Avenzo, C.; Pannaccione, A.; Secondo, A.; Casamassa, A.; Formisano, L.; Guida, N.; Annunziato, L. Silencing or knocking out the $\mathrm{Na}^{+} / \mathrm{Ca}^{2+}$ exchanger-3 (NCX3) impairs oligodendrocyte differentiation. Cell Death Differ. 2012, 19, 562-572. [CrossRef]

16. Sokolow, S.; Manto, M.; Gailly, P.; Molgo, J.; Vanderbrouck, C.; Vanderwinden, J.-M.; Herchuelz, A.; Schurmans, S. Impaired neuromuscular transmission and skeletal muscle fiber necrosis in mice lacking $\mathrm{Na} / \mathrm{Ca}$ exchanger 3. J. Clin. Invest. 2004, 113, 265-293. [CrossRef]

17. Molinaro, P.; Viggiano, D.; Nistico, R.; Sirabella, R.; Secondo, A.; Boscia, F.; Pannaccione, A.; Scorziello, A.; Mehdawy, B.; Sokolow, S.; et al. $\mathrm{Na}^{+}-\mathrm{Ca}^{2+}$ exchanger (NCX3) knock-out mice display an impairment in hippocampal long-term potentiation and spatial learning and memory. J. Neurosci. 2011, 31, 7312-7321. [CrossRef]

18. Jeffs, G.J.; Meloni, B.P.; Sokolow, S.; Herchuelz, A.; Schurmans, S.; Knuckey, N.W. NCX3 knockout mice exhibit increased hippocampal CA1 and CA2 neuronal damage compared to wild-type mice following global cerebral ischemia. Exp. Neurol. 2008, 210, 268-273. [CrossRef]

19. Molinaro, P.; Cuomo, O.; Pignataro, G.; Boscia, F.; Sirabella, R.; Pannaccione, A.; Secondo, A.; Scorziello, A.; Adornetto, A.; Gala, R.; et al. Targeted Disruption of $\mathrm{Na}^{+} / \mathrm{Ca}^{2+}$ exchanger (NCX3) gene leads to a worsening of ischemic brain damage. J. Neurosci. 2008, 28, 1179-1184. [CrossRef]

20. Gabellini, N.; Bortoluzzi, S.; Danieli, G.A.; Carafioli, E. Control of the $\mathrm{Na}^{+} / \mathrm{Ca}^{2+}$ exchanger 3 promoter by cyclic adenosine monophosphate and $\mathrm{Ca}^{2+}$ in differentiating neurons. J. Neurochem. 2003, 84, 282-293. [CrossRef]

21. Formisano, L.; Saggese, M.; Secondo, A.; Sirabella, R.; Vito, P.; Valsecchi, V.; Molinaro, P.; Di Renzo, G.; Annunziato, L. The two isoforms of the $\mathrm{Na}^{+} / \mathrm{Ca}^{2+}$ exchanger, $\mathrm{NCX} 1$ and $\mathrm{NCX} 3$, constitute novel additional targets for the prosurvival action of Akt/protein kinase B pathway. Mol. Pharm. 2008, 73, 727-737. [CrossRef]

22. Sirabella, R.; Secondo, A.; Pannaccione, A.; Molinaro, P.; Formisano, L.; Guida, N.; Di Renzo, G.; Annunziato, L.; Cataldi, M. ERK1/2, p38, and JNK regulate the expression and the activity of the three isoforms of the $\mathrm{Na}^{+} / \mathrm{Ca}^{2+}$ exchanger, $\mathrm{NCX} 1, \mathrm{NCX} 2$, and NCX3, in neuronal PC12 cells. J. Neurochem. 2012, 122, 911-922. [CrossRef] [PubMed]

23. Jonas, E.A.; Porter, G.A.; Alavian, K.N. Bcl-xL in neuroprotection and plasticity. Front. Physiol. 2014, 5, 355. [CrossRef] [PubMed] 
24. Wood-Kaczmar, A.; Deas, E.; Wood, N.W.; Abramov, A.Y. The role of mitochondrial NCX in the mechanism of neurodegeneration in Parkinson's disease. Adv. Exp. Med. 2013, 961, 241-249. [CrossRef]

25. Krajewska, M.; Mai, J.K.; Zapata, J.M.; Ashwell, K.W.S.; Schendel, S.L.; Reed, J.C.; Krajewski, S. Dynamics of expression of apoptosis-regulatory proteins Bid, Bcl-2, Bcl-X, Bax and Bak during development of murine nervous system. Cell Death Differ. 2002, 9, 145-157. [CrossRef]

26. Lotharius, J.; Barg, S.; Wiekop, P.; Lundberg, C.; Raymon, H.K.; Brundin, P. Effect of mutant a-synuclein on dopamine homeostasis in a new human mesencephalic cell line. J. Biol. Chem. 2002, 41, 38884-38894. [CrossRef]

27. Choi, H.K.; Won, L.A.; Kontur, P.J.; Hammond, D.N.; Fox, A.P.; Wainer, B.H.; Hoffmann, P.C.; Heller, A. Immortalization of embryonic mesencephalic dopaminergic neurons by somatic cell fusion. Brain Res. 1991, 552, 67-76. [CrossRef]

28. Liou, G.-Y.; Storz, P. Detecting reactive oxygen species by immunohistochemistry. Methods Mol. Biol. 2015, 1292, 97-104. [CrossRef]

29. Ayala, A.; Munoz, M.F.; Argüelles, S. Lipid peroxidation: Production, metabolism, and signaling mechanisms of malondialdehyde and 4-hydroxy-2-noneal. Oxid. Med. Cell. Longev. 2014, 360438. [CrossRef]

30. Secondo, A.; Staiano, R.I.; Scorziello, A.; Sirabella, R.; Boscia, F.; Adornetto, A.; Valsecchi, V.; Molinaro, P.; Canzoniero, L.M.; Di Renzo, G.; et al. BHK cells transfected with NCX3 are more resistant to hypoxia followed by reoxygenation than those transfected with NCX1 and NCX2: Possible relationship with mitochondrial membrane potential. Cell Calcium 2007, 42, 521-535. [CrossRef]

31. Cai, Q.; Ma, T.; Tian, Y.; Li, C.; Li, H. Catalpol inhibits ischemia-induced premyelinating oligodendrocyte damage through regulation of intracellular calcium homoeostasis via $\mathrm{Na}^{+} / \mathrm{Ca}^{2+}$ exchanger 3. Int. J. Mol. Sci. 2018, 19, 1925. [CrossRef]

32. Dünker, N.; Krieglstein, K. Targeted mutations of transforming growth factor-beta genes reveal important roles in mouse development and adult homeostasis. Eur. J. Biochem. 2000, 267, 6982-6988. [CrossRef] [PubMed]

33. Parpura, V.; Sekler, I.; Fern, R. Plasmalemmal and mitochondrial $\mathrm{Na}^{+} / \mathrm{Ca}^{2+}$ exchange in neuroglia. Glia 2016, 64, 1646-1654. [CrossRef] [PubMed]

34. Gandhi, S.; Wood-Kaczmar, A.; Yao, Z.; Plun-Favreau, H.; Deas, E.; Klupsch, K.; Downward, J.; Latchman, D.S.; Tabrizi, S.J.; Wood, N.W.; et al. Pink1-associated Parkinson's disease is caused by neuronal vulnerability to calcium-induced cell death. Mol. Cell 2009, 33, 627-638. [CrossRef] [PubMed]

35. Fu, Y.H.; Paxinos, G.; Watson, C.; Halliday, G.M. The substantia nigra and ventral tegmental dopaminergic neurons from development to degeneration. J. Chem. Neurol. 2016, 76, 98-107. [CrossRef]

36. Zhong, H.; Yin, H. Role of lipid peroxidation derived 4-hydroxynonenal (4-HNE) in cancer: Focusing on mitochondria. Redox Biol. 2015, 4, 193-199. [CrossRef]

37. Barrera, G.; Pizzimenti, S.; Ciamporcero, E.S.; Daga, M.; Ullio, C.; Arcaro, A.; Cetrangolo, G.P.; Ferretti, C.; Dianzani, C.; Lepore, A.; et al. Role of 4-Hydroxynonenal-Protein Adducts in Human Diseases. Antioxid. Redox Signal. 2014, 22, 1681-1702. [CrossRef]

38. Mao, L.; Zuo, M.-L.; Hu, G.-H.; Duan, X.-M.; Yang, Z.-B. Mir-193 targets ALDH2 and contributes to toxic aldehyde accumulation and tyrosine hydroxylase dysfunction in cerebral ischemia/reperfusion injury. Oncotarget 2017, 8, 99681-99692. [CrossRef]

39. Yoritaka, A.; Hattori, N.; Uchida, K.; Tanaka, M.; Stadman, E.R.; Mizuno, Y. Immunohistochemical detection of 4-hydroxynonenal protein adducts in Parkinson disease. Proc. Natl. Acad. Sci. USA 1996, 93, 2696-2701. [CrossRef]

40. Chytil, A.; Magnuson, M.A.; Wright, C.V.; Moses, H.L. Conditional inactivation of the TGF-beta type II receptor using Cre: Lox. Genesis 2002, 32, 73-75. [CrossRef]

41. Kimmel, R.; Turnbull, D.H.; Blanquet, V.; Wurst, W.; Loomis, C.A.; Joyner, A.L. Two lineage boundaries coordinate vertebrate apical ectodermal ridge formation. Genes Dev. 2000, 14, 1377-1389.

42. Roussa, E.; Wiehle, M.; Dünker, N.; Becker-Catins, S.; Oehlke, O.; Krieglstein, K. Transforming growth factor beta is required for differentiation of mouse mesencephalic progenitors into dopaminergic neurons in vitro and in vivo: Ectopic induction in dorsal mesencephalon. Stem. Cells 2006, 24, 2120-2129. [CrossRef] [PubMed] 
43. Dong, Y.; Heien, M.L.; Maxson, M.M.; Ewing, A.G. Amperometric measurements of catecholamine release from single vesicles in MN9D cells. J. Neurochem. 2008, 107, 1589-1595. [CrossRef] [PubMed]

44. Oehlke, O.; Schlosshardt, C.; Feuerstein, M.; Roussa, E. Acidosis-induced V-ATPase trafficking in salivary ducts is initiated by cAMP/PKA/CREB pathway via regulation of Rab11b expression. Int. J. Biochem. Cell Biol. 2012, 44, 1254-1265. [CrossRef] [PubMed]

(C) 2020 by the authors. Licensee MDPI, Basel, Switzerland. This article is an open access article distributed under the terms and conditions of the Creative Commons Attribution (CC BY) license (http://creativecommons.org/licenses/by/4.0/). 